\title{
Molecular analysis of the cso operon of enterotoxigenic Escherichia coli reveals that CsoA is the adhesin of CS1 fimbriae and that the accessory genes are interchangeable with those of the cfa operon
}

\author{
Marie B. Marron and Cyril J. Smyth \\ Author for correspondence: Marie B. Marron. Tel: +3531702 1195. Fax: +35316799294.
}

Department of

Microbiology, Moyne Institute of Preventive Medicine, Trinity College, University of Dublin, Dublin 2, Republic of Ireland

\begin{abstract}
A deletion mutation in CSOA, the gene encoding the structural subunit protein of CS1 fimbriae of enterotoxigenic Escherichia coli of serotype 06:K15:H16 or $\mathbf{H}-$, was constructed in the subcloned CS1 genetic determinant. The mutation resulted in the abolition of CS1 fimbrial adhesiveness. Complementation, in trans, involving the determinant with the csoA deletion mutation and the gene encoding the structural subunit protein, CsOA, expressed from compatible plasmids, restored the expression and adhesive ability of CS1 fimbriae. In addition, trans-complementation was achieved between the cso determinant with the aforementioned deletion mutation and the cfaB gene encoding the structural subunit protein (CfaB) of CFA/ fimbriae, resulting in the expression of CFA/l fimbriae. The observation that heterologous assembly was possible between these two fimbrial systems, together with the knowledge that the adhesin of CFAl fimbriae is the structural subunit, was exploited to investigate whether CsoA had adhering properties. A deletion mutation in CfaB was created in the CFAl fimbrial determinant.

Complementation of this mutation with csoA in trans resulted in expression of the CsoA antigen on the bacterial cell surface and restoration of bacterial adherence. As no minor subunits act as the adhesin in CFAl fimbriae, adhesion was mediated by CsOA. Nucleotide sequencing of the DNA region downstream from csoA confirmed the absence of genes encoding minor subunits which might act as the adhesin. Two open reading frames were revealed which encoded proteins sharing considerable homology with proteins encoded by corresponding ORFs in the CFA/ fimbrial operon. These proteins underlie the functional similarities between the CS1 and CFAI fimbrial systems, allowing heterologous expression of their respective subunits.
\end{abstract}

Keywords: CS1 fimbriae, adhesin, CsoA, CFA/I fimbriae, interchangeability in assembly system

\section{INTRODUCTION}

Enterotoxigenic Escherichia coli (ETEC) are an important cause of diarrhoea in children in Third World countries, in travellers and in domestic animals. Their virulence is associated with adherence to the intestinal epithelium by means of fimbriae and subsequent production of heat-

Abbreviations: CFA, colonization factor antigen; ETEC, enterotoxigenic E. coli. labile enterotoxin (LT) or heat-stable enterotoxin (ST) or both (Cravioto et al., 1982) The diversity of serologically distinct fimbrial antigens expressed independently by human ETECs exemplifies bacterial ingenuity in adapting and evading the host's immune responses (de Graaf \& Gaastra, 1994).

CFA/I and CFA/II fimbriae are two types of colonization factor antigens expressed independently by different serovars of human ETEC (Evans et al., 1975; Evans \& Evans, 1978). CFA/II is a fimbrial complex consisting of 
three coli surface antigens, designated CS1, CS2 and CS3 (Smyth, 1982). Expression of CS1 or CS2 fimbriae is found almost exclusively on human ETEC strains of serotype O6: $\mathrm{K} 15: \mathrm{H} 16$ or $\mathrm{H}-$. CS1 and CS2 fimbriae are expressed in a biotype-dependent fashion, namely, CS1 fimbriae by strains of biotype A, and CS2 fimbriae by strains of biotypes B, C and F (Smyth, 1986). Therefore, CS1 and CS2 fimbriae cannot be co-expressed, but individually they are co-expressed with CS3 fimbriae. Although these colonization factor antigens exhibit distinct immunological properties, extensive amino acid homology is observed between the subunit proteins of CFA/I and CS1 fimbriae (Perez-Casal $e t$ al., 1990; Jordi $e t$ al., 1991). The conservation of these regions of homology suggests the possible existence of similarities in the biogenesis systems for these fimbriae. Furthermore, these fimbriae share the property of agglutinating bovine erythrocytes. However, the nature of the receptor or receptors recognized by these fimbriae has not been conclusively determined (de Graaf \& Gaastra, 1994).

It has been shown that both fimbrial operons are expressed from large molecular mass plasmids in their respective wild-type strains (Smith et al., 1982; Perez-Casal et al., 1990). Expression from these operons is under environmental regulation mediated by DNA-binding proteins of the AraC family, Rns regulating CS1 fimbrial expression and $\mathrm{CFaD}$ regulating the expression of CFA/I fimbriae (Caron et al., 1989; Savelkoul et al., 1990). These proteins are homologous and interchangeable; Rns can regulate expression from the CFA/I operon while $\mathrm{CfaD}$ can mediate expression from the CS1 operon.

At the inception of this study the organization of the CS1 operon [designated cso by Jordi et al. (1991) and agreed with our laboratory, or coo by Perez-Casal et al. (1990) and Scott $e$ t al. (1992)] had not been well characterized. CS1 fimbriae are composed of a $16 \mathrm{kDa}$ major subunit protein, CsoA, which is expressed from the CS1 genetic determinant within a $7 \mathrm{~kb}$ DNA region (Perez-Casal et al., 1990; Jordi et al., 1991). A $26 \mathrm{kDa}$ protein, CsoB, had also been identified which was proposed to have a role in fimbrial assembly but not in transport of the subunits (Scott et al., 1992). The remaining coding capacity of the CS1 determinant had not been detailed, but was thought to encode additional components necessary for the biogenesis of CS1 fimbriae, by analogy with the organization of other fimbrial operons, such as the pap operon (Hultgren et al., 1991).

The organization of the CFA/I fimbrial operon (cfa) had been determined (Jordi et al., 1992). The structural subunit protein, $\mathrm{CfaB}$, together with three other proteins, $\mathrm{CfaA}, \mathrm{CfaC}$ and $\mathrm{CfaE}$, are expressed from region 1 of the high molecular mass plasmid while $\mathrm{CfaD}$ is expressed from region 2 of the same plasmid. A fifth gene is encoded in region 1 which is homologous to the regulatory gene $c f a D$; however, it is non-functional and is called $c f a D^{\prime}$ (Gaastra et al., 1990). The functions of the proteins CfaA, $\mathrm{CfaC}$ and $\mathrm{CfaE}$ are unknown. It is conceivable that these proteins are the components of a biogenesis system. Indeed, $\mathrm{CfaC}$ is a high molecular mass protein with properties characteristic of an outer-membrane protein and may perform the role of an usher, although it does not show any homology with known ushers which make up the biosynthetic machinery of other fimbriae (Kusters \& Gaastra, 1994). In contrast to Pap, S and type 1 fimbriae, minor fimbrial components do not appear to be encoded by the $c f a$ fimbrial system (de Graaf \& Gaastra, 1994; Smyth et al., 1994). The structural subunit of CFA/I fimbriae was characterized biochemically as the adhesin of this fimbrial system (Bühler et al., 1991). By comparison, the nature of the CS1 fimbrial adhesin is unknown and the possible existence of minor subunits has not been demonstrated. The major subunit gene may in the correct orientation at the fimbrial tip act as the adhesin. Alternatively, the adhesin and the structural subunit may be encoded by separate genes as is the case with P, S and type 1 fimbriae (Smyth et al., 1994). Furthermore, the steps in the biogenesis of CS1 fimbriae remain unelucidated.

This study employed a molecular genetic approach to ascertain the adhesin responsible for CS1 fimbrial adhesiveness. The role of CsoA, the major fimbrial antigen, in the adhering function of CS1 fimbriae was investigated. A deletion mutation in the cso $A$ gene was constructed in the subcloned CS1 genetic determinant and the effects of this mutation on the expression and properties of CS1 fimbriae were ascertained. Heterologous subunit expression and assembly between the CS1 and CFA/I fimbrial systems was assessed using genetically constructed strains.

\section{METHODS}

Bacterial strains and plasmids. E. coli strains E90a and C922a2 are wild-type enterotoxigenic strains of serotype O6:K15:H16, which are positive and negative, respectively, for CS1 fimbrial expression (Smyth, 1982). E. coli strains H10407 and H10407-P are wild-type enterotoxigenic strains of serotype O78: H11, which are positive and negative, respectively, for CFA/I fimbrial expression (Evans et al., 1975). E. coli strain $54 \mathrm{R} 118$ is an E. coli $\mathrm{K} 12$ recombinant strain positive for $\mathrm{CFA} / \mathrm{I}$ fimbriae (McConnell et al., 1981). E. coli strain XL1-Blue [rec A1 end $A 1$ gyr $A 96$ thi-1 bsdR17 supE44 relA1 lac $\left(\mathrm{F}^{\prime}\right.$ pro $A B$ lac $I^{q} Z$ $\left.\left.\Delta M 15, \operatorname{Tn} 10\left(\mathrm{Tet}^{\mathrm{r}}\right)\right)\right]$ (Stratagene) was used as the host for molecular cloning and expression, and was maintained on LB agar supplemented with the appropriate antibiotics at the following concentrations: ampicillin $\left(100 \mu \mathrm{g} \mathrm{ml}^{-1}\right)$, chloramphenicol $\left(30 \mu \mathrm{g} \mathrm{ml}^{-1}\right)$, tetracycline $\left(10 \mu \mathrm{g} \mathrm{ml}^{-1}\right)$, spectinomycin $\left(50 \mu \mathrm{g} \mathrm{ml}^{-1}\right)$. Restriction endonucleases were purchased from New England Biolabs and Boehringer Mannheim. The plasmids used in this study are described in Table 1.

Subcloning the CS1 operon and the CSOA gene separately. HindIII digestion of plasmid pSS4180 generates a $13 \mathrm{~kb}$ HindIII fragment with two internal ClaI sites (Fig. 1a). These ClaI sites delimit the first gene, $c s o B$, of the CS1 operon and, in addition, the second $\mathrm{ClaI}$ site is positioned $5^{\prime}$ to the $\operatorname{cso} A$ gene, the major subunit gene. Partial digestion with ClaI of the $13 \mathrm{~kb}$ HindIII fragment generates a $7 \mathrm{~kb}$ ClaI-HindIII fragment with the second internal ClaI site. This fragment encodes the CS1 fimbrial operon. The $7 \mathrm{~kb}$ ClaI-HindIII fragment was ligated to the plasmid pGEM-9Zf cleaved at its AccI and HindIII sites (Fig. 1b). The cohesive ends of the $A c c \mathrm{I}$ and ClaI recognition sites are compatible and are not recleavable with either enzyme. Therefore, the internal ClaI site is rendered unique. The 
Table 1. Plasmids used in this study

\begin{tabular}{|c|c|c|c|}
\hline Plasmid & Description* & Replicon & Source or reference \\
\hline pBluescript & Phagemid derived from $\mathrm{pUC19}, \mathrm{Amp}^{\mathrm{r}}$ & ColE1 & Stratagene \\
\hline $\begin{array}{l}\text { pGEM- } \\
7 \mathrm{Zf}(-) / 9 \mathrm{Zf}(-)\end{array}$ & $\begin{array}{l}\text { Standard vectors, blue/white selection, } \\
A m p^{r}\end{array}$ & ColE1 & Promega \\
\hline pACYC184 & Cloning vector, $\mathrm{Cm}^{\mathrm{r}} \mathrm{Tc}^{\mathrm{r}}$ & $\mathrm{p} 15 \mathrm{~A}$ & Chang \& Cohen (1978) \\
\hline pCL1921 & Low-copy-number cloning vector, $\mathrm{Spc}^{\mathrm{r}}$ & pSC101 & Lerner \& Inouye (1990) \\
\hline pLG339 & $\begin{array}{l}\text { Low-copy-number cloning vector, } \\
\operatorname{Tc}^{r} \operatorname{Kan}^{r}\end{array}$ & pSC101 & Stoker et al. (1982) \\
\hline pSS4180 & $\begin{array}{l}\text { CS1 operon within a } 15 \mathrm{~kb} \text { Sall DNA } \\
\text { region cloned from total DNA of } E \text {. } \\
\text { coli C921b-1 in pLG339 }\end{array}$ & pSC101 & $\begin{array}{l}\text { S. G. J. Smith (Dept of } \\
\text { Microbiology, } \\
\text { University of Dublin), } \\
\text { unpublished data }\end{array}$ \\
\hline pNTP513 & $\mathrm{CFA} / \mathrm{I}$ region $\mathrm{I}$ in $\mathrm{pACYC} 184$ & $\mathrm{p} 15 \mathrm{~A}$ & Willshaw et al. (1983) \\
\hline pMM101 & CS1 operon cloned in pGEM-9Zf(-) & ColE1 & \\
\hline pMM102 & cso $A$ cloned in pBluescript $\mathrm{KS}$ & ColE1 & \\
\hline pMM1021 & $\Delta c s o A$ cloned in pBluescript $\mathrm{KS}$ & ColE1 & \\
\hline pMM103 & pMM101 $\Delta c s o A$ & ColE1 & \\
\hline pMM104 & CS1 operon cloned in pACYC184 & $\mathrm{p} 15 \mathrm{~A}$ & \\
\hline pMM1041 & pMM104 $\Delta c s o A$ & $\mathrm{p} 15 \mathrm{~A}$ & This study \\
\hline pMM301 & $c f a B$ cloned in pGEM-9Zf $(-)$ & ColE1 & Alus stuay \\
\hline pMM7011 & $c f a C$ and $c f a E$ cloned in pGEM-7Zf $(-)$ & ColE1 & \\
\hline pMM7013 & $\begin{array}{l}c f a A \Delta c f a B c f a C c f a E \text { cloned in pGEM- } \\
7 \mathrm{Zf}(-)\end{array}$ & ColE1 & \\
\hline pMM8102 & cso $A$ cloned in pACYC184 & $\mathrm{p} 15 \mathrm{~A}$ & \\
\hline pMM8301 & $c f a B$ cloned in $\mathrm{pACYC} 184$ & $\mathrm{p} 15 \mathrm{~A}$ & \\
\hline pSS2192 & rns cloned in PCL1921 & pSC101 & $\begin{array}{l}\text { S. G. J. Smith (Dept of } \\
\text { Microbiology, } \\
\text { University of Dublin), } \\
\text { unpublished data }\end{array}$ \\
\hline
\end{tabular}

*Amp ${ }^{r}$, ampicillin resistance; $\mathrm{Cm}^{\mathrm{r}}$, chloramphenicol resistance; $\mathrm{Tc}^{\mathrm{r}}$, tetracycline resistance; $\mathrm{Kan}^{\mathrm{r}}$, kanamycin resistance; $\mathrm{Spc}^{\mathrm{r}}$, spectinomycin resistance.

recombinant plasmid thus generated was designated pMM101. The $7 \mathrm{~kb} \mathrm{CS1}$ genetic determinant was then subcloned from pMM101 as an Ecl136II-HindIII fragment into the EcoRV-HindIII sites in vector pACYC184 to yield pMM104. This was possible due to the cleavage of the $\mathrm{SacI}$ recognition site in the multiple cloning site of pGEM-9Zf immediately $5^{\prime}$ to the CS1 genetic determinant inserted into pMM101 by the restriction enzyme Ecl136II in a blunt-ended manner (Fig. 1b). This achieves compatibility with the blunt-ended EcoRV recognition site in $\mathrm{PACYC} 184$.

To subclone the $\operatorname{cso} A$ gene separately, pSS4180 was digested with $C l a I$ and $X b a I$ and the resulting $700 \mathrm{bp} \mathrm{ClaI-XbaI} \mathrm{fragment}$ was ligated with the ClaI-XbaI-cleaved vector plasmid pBluescript KS (pBKS, Stratagene) to yield the recombinant plasmid pMM102 (Fig. 1c). The orientation of the cso $A$ gene in pMM102 ensures that its expression may be directed from the lac $Z$ promoter of $\mathrm{pBKS}$ when this promoter is derepressed by the inducer IPTG. The $\operatorname{cso} A$ gene was also subcloned into the vector plasmid pACYC184 to create pMM8102.

Creating a deletion mutation in the CS1 operon. The $700 \mathrm{bp}$ $C l a \mathrm{I}-X b a \mathrm{I}$ fragment encoding the $\operatorname{cso} A$ gene contains four internal $M s e I$ sites (Fig. 1d). Digestion of this fragment with $M s e \mathrm{I}$ and subsequent ligation of the two end fragments (i.e. the $80 \mathrm{bp} C l a \mathrm{I}-\mathrm{MseI}$ fragment and the $51 \mathrm{bp} M s e \mathrm{I}-\mathrm{XbaI}$ fragment) yielded a 127 bp DNA fragment which was subcloned into pBKS to yield pMM1021 (Fig. 1e). Nucleotide sequencing of the insert in pMM1021 confirmed that the correct DNA fragments were ligated. The complete cso $A$ gene had been

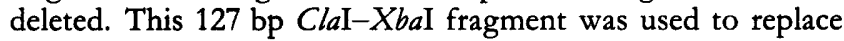
the $700 \mathrm{bp} \mathrm{ClaI-XbaI} \mathrm{fragment} \mathrm{encoding} \mathrm{cso} A$ in pMM101. The resultant recombinant plasmid was designated pMM103 (Fig. 1f). Plasmid pMM1041 was produced from pMM103 and pACYC184 by cleavage of the Ecl13GI-HindIII fragment in pMM103 and ligation to the EcoRV-HindIII sites in the vector pACYC184.

Subcloning the CFA/I fimbrial subunit. Plasmid pNTP513 is a pACYC184 derivative encoding the region 1 genes of the CFA/I fimbrial system within an $8 \mathrm{~kb}$ DNA region (Fig. 2a). cf $a B$, the CFA/I fimbrial subunit gene, is encoded on a $1.3 \mathrm{~kb}$ $X b a I-H i n d I I I ~ D N A$ fragment (Fig. 2b) within this $8 \mathrm{~kb}$ DNA region. This $1.3 \mathrm{~kb} \mathrm{XbaI-HindIII} \mathrm{fragment} \mathrm{was} \mathrm{ligated} \mathrm{to}$ vector plasmid pGEM-9Zf to create pMM301, a high-copynumber ColE1 plasmid expressing $\mathrm{CfaB}$. It was also ligated to $X b a \mathrm{I}-H$ indIII-cleaved vector plasmid pACYC184 to create pMM8301.

Creating a deletion mutation in the CFA/1 operon. The deletion of the $c f a B$ gene in the CFA/I operon was achieved in a three-step process. Firstly, the genetic determinant was removed from pNTP513 by digestion with EcoRV endonuclease. This excluded most of the $c f a D^{\prime}$ gene, which is nonfunctional (Fig. 2a). Secondly, digestion of the unique BamHI site at the $3^{\prime}$ end of $c f a B$ resulted in a 4033 bp fragment which 
(a) $\stackrel{H}{L}$

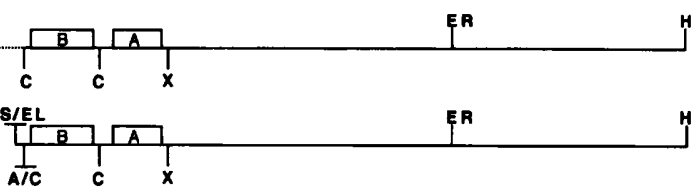

(c)

(d)

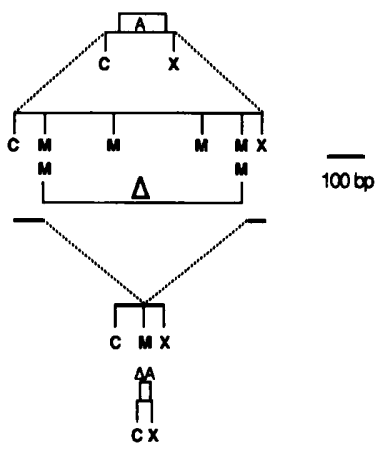

(f)

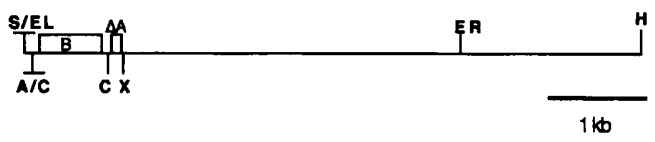

(a)

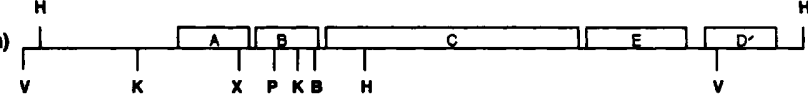

(b)

(c)

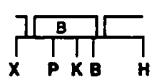

(d)

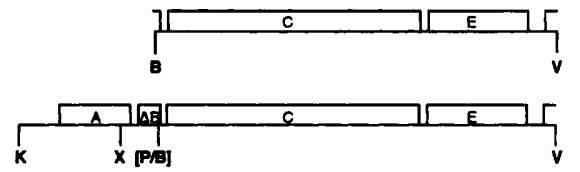

$1 \mathrm{~kb}$

Fig. 2. Construction of the deletion in the CFAI operon. The CFAl operon is encoded within an $8 \mathrm{~kb}$ DNA region of pNTP513 (a). The $c f a B$ gene was subcloned as a $1.3 \mathrm{~kb} X$ bal-HindIII DNA region (b) into the appropriately cleaved vector plasmids pGEM-9Zf and pACYC184 to create pMM301 and pMM8301, respectively. Construction of the deletion in the $c \mathrm{fa} B$ gene of the CFAI operon was achieved as follows. The BamHI-ECoRV $4 \mathrm{~kb}$ DNA region (c) was subcloned into pGEM-7Zf to create pMM7011, which was cleaved at the unique BamHI site and this site then filled in to produce a blunt end. pMM7011 was then cut at the Kpnl site in the vector DNA and the $1.3 \mathrm{~kb} K$ phl-Pvull DNA fragment from the CFAI region 1 (a) was ligated to these sites in pMM7011 to create pMM7013 (d). This resulted in the deletion of the gene $c f a B(\Delta B)$. Abbreviations: $B, B a m H I ; H$, HindIII; K, Kpnl; P, Pvull; V, EcoRV; X, Xbal. cfa genes are represented by boxes with single-letter designations.

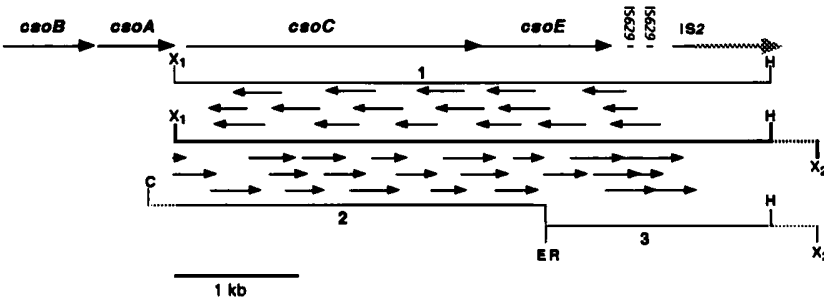

Fig. 3. Strategy for sequencing the DNA region downstream from the csoA gene of the CS1 operon. All DNA regions indicated [the $5.5 \mathrm{~kb} X$ bal-HindIII DNA region (1), the $3.7 \mathrm{~kb}$ Clal-EcoRI DNA region (2) and the $3 \mathrm{~kb}$ EcoRI-Xbal DNA region (3)] were subcloned separately into the vector pGEM-7Zf and deletions were generated from the appropriate sites, indicated by the direction of the arrows, using the Erase-a-Base kit (Promega). The positions of the open reading frames are indicated above the sequencing strategy diagram. In the DNA approximately $200 \mathrm{bp}$ downstream from the csoE gene, two regions ( $100 \mathrm{bp}$ apart) of $48 \mathrm{bp}$ and $67 \mathrm{bp}$ share $89 \%$ and $84 \%$ sequence similarity, respectively, with IS629. Downstream of these sequences $(250 \mathrm{bp})$, approximately 100 bases sequenced showed $100 \%$ identity with part of the sequence of IS2. The shaded arrow represents the additional DNA region sequenced by Froehlich et al. (1994). This complete region shares $99 \%$ identity with the first 877 bases of IS2. Abbreviations: C, Clal; ER, EcoRI; $H$, HindIII; $X_{1}, X$ bal; $X_{2}, X$ Xal site $3^{\prime}$ to the CS1 operon in pMM104 from which this DNA region was subcloned. Broken lines represent DNA regions which are not drawn to scale.

3. Searches for nucleotide and amino acid sequence similarities were performed with the BLAST family of programs in the EMBL and GenBank databases (Altschul et al., 1990). Com- 
parison of protein sequences was performed with the Clustal V program (Higgins \& Sharp, 1989).

Antibodies. Anti-CS1 antibodies were raised to CS1 antigen purified from E. coli XL1-Blue expressing CS1 fimbriae from the recombinant plasmid pMM101. The antigen was prepared from CFA-broth-grown (Evans et al., 1975) E. coli XL1Blue(pMM101) by homogenization (Ultra-turrax, Janke \& Kunkel) followed by ammonium sulphate precipitation and Phenyl-Sepharose (Pharmacia) column chromatography. New Zealand White rabbits were given four injections, intramuscularly, of purified fimbriae ( $40 \mu \mathrm{g}$ protein per dose) in Freund's complete adjuvant on day 0 , and in Freund's incomplete adjuvant on days 7,14 and 21. Following absorption with appropriate strains (Smyth, 1982), the specific anti-CS1 antibodies were purified according to Harboe \& Ingild (1973). To raise anti-CFA/I antibodies, rabbits were inoculated intravenously, according to the schedule of Evans et al. (1975), with formalin-treated whole-cell suspensions of ETEC strain H10407 of serotype O78:H11 expressing CFA/I fimbriae. The serum was absorbed with E. coli strain H10407-P, a spontaneous CFA/I-negative variant (Smyth et al., 1979), and the antibodies purified as above. The specificities of these purified immunoglobulins were checked by immunodiffusion and agglutination tests before use.

Immuno-techniques. E. coli XL1-Blue recombinants were grown overnight at $37^{\circ} \mathrm{C}$ in $\mathrm{LB}$ broth supplemented with the appropriate antibiotics. The cultures were standardized and heat-released extracts were obtained as described by Smyth (1982). The heat-released extracts were analysed by SDS-PAGE, which was performed using the method of Laemmli (1970). Molecular mass standards were obtained from Sigma. Electroblotting was performed according to Towbin et al. (1979). For immunodetection, anti-CS1 or anti-CFA/I antiserum was used as the primary antibody and swine anti-rabbit IgG conjugated to peroxidase (DAKO) was used as the secondary antibody. The blots were developed using 4-chloro-1-naphthol (Sigma) as substrate in the peroxidase reaction. Slide agglutination tests were used to rapidly detect expression of fimbriae.

Immuno-electron microscopy. E. coli XL1-Blue recombinants were dried onto Formvar-coated 400-mesh gold grids and incubated in anti-CS1 antibodies diluted 1:100 in distilled water. Unbound antibodies were removed with four $1 \mathrm{~min}$ washes in distilled water. This was followed by incubation in Protein A-gold conjugates (10 nm particles, Sigma) diluted $1: 10$ in distilled water. Unbound gold conjugate was removed by four $1 \mathrm{~min}$ washes in distilled water. The grids were blotted dry, negatively stained with $1 \%(\mathrm{w} / \mathrm{v})$ phosphotungstic acid and viewed using a Hitachi $\mathrm{H} 7000$ transmission electron microscope.

Haemagglutination. Adherence to bovine erythrocytes was tested in a haemagglutination assay with $E$. coli XL1-Blue recombinants. The assay was done essentially as described by Smyth (1982), in the presence of $1 \%(\mathrm{w} / \mathrm{v}) \mathrm{D}(+)$ mannose.

\section{RESULTS}

The deletion mutation in the cSOA gene is complemented when the csoA gene is provided in trans

The CsoA antigen was detected by immunoblotting using anti-CS1 antibodies (Fig. 4). The CsoA protein was expressed from the CS1 genetic determinant in pMM104 (lane 3 ) and from pMM102 expressing the cso $A$ gene (lane

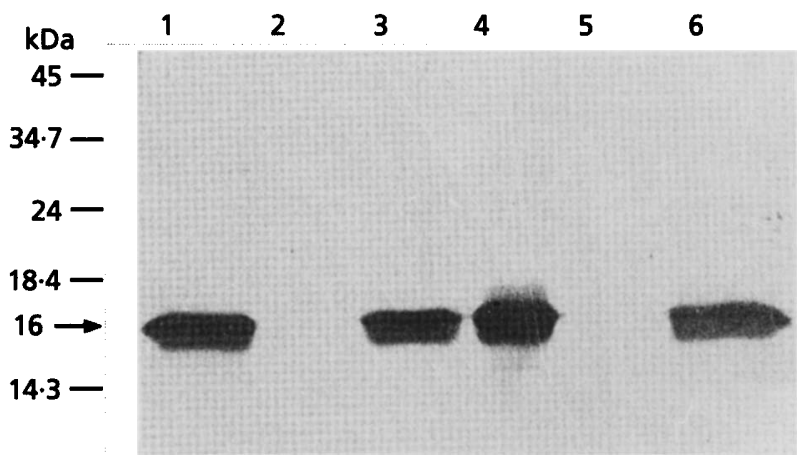

Fig. 4. Western blot analysis of expression of the CsoA antigen from recombinant plasmids. Heat-released extracts from wildtype ETEC and $E$. coli XL1-Blue harbouring recombinant plasmids with the DNA inserts described in Methods were probed with anti-CS1 antiserum. Lanes: 1, strain E90a $\left(\mathrm{CS}^{+}{ }^{+}\right) ; 2$, strain C922a-2 (CS1 $\left.{ }^{-}\right)$; 3, strain XL1-Blue(pMM104); 4, strain XL1-Blue(pMM102); 5 strain XL1-Blue(pMM1041); 6, strain XL1Blue(pMM1041 and pMM102). The CsOA antigen is indicated at $16 \mathrm{kDa}$. Molecular mass standards (Sigma) are indicated on the left. The apparent shadowing effect is caused by protein overloading.

4) in E. coli XL1-Blue. Expression was not detected in $E$. coli XL1-Blue harbouring pMM1041 (cso $A$ deletion mutant) (lane 5). However, when the $\operatorname{cso} A$ gene (pMM102) was expressed in trans to pMM1041, the CsoA protein was detected (lane 6). The Rns protein, encoded by pSS2192, was not required in these experiments because the DNA region with which this protein interacts to abolish the negative regulation of expression was excluded in the subcloning of the cso operon.

To determine how this related to the production of intact fimbriae, immuno-electron microscopy was used. As Fig. 5(a) shows, the CS1 genetic determinant directed the expression of morphologically intact CS1 fimbriae in $E$. coli XL1-Blue. Deletion of the cso $A$ gene from the CS1 operon arrested expression of CS1 fimbriae (Fig. 5b). Moreover, CS1 fimbriae were not expressed from the recombinant strain harbouring pMM102, which encodes the $\operatorname{cso} A$ gene only (data not shown). However, E. coli XL1-Blue expresses type 1 fimbriae as detected by immuno-electron microscopy (data not shown). Thus, the biogenesis system of type 1 fimbriae does not direct surface expression of the CsoA antigen on E. coli XL1Blue(pMM102) expressing the cso $A$ gene of the CS1 operon. Complementation of the deletion mutation in the cso $A$ gene in pMM1041 by expression of CsoA in trans from pMM102 restored the biogenesis of morphologically intact CS1 fimbriae (Fig. 5c). This verified that the cso $A$ mutation created was non-polar.

\section{CFA/I fimbriae are produced when the deletion mutation in the CSOA gene is complemented by the cfaB gene expressed in trans}

Because of the extensive amino acid sequence homology between $\mathrm{Cso} A$ and $\mathrm{CfaB}$, experiments were performed to determine if the $c f a B$ gene encoding the structural subunit 

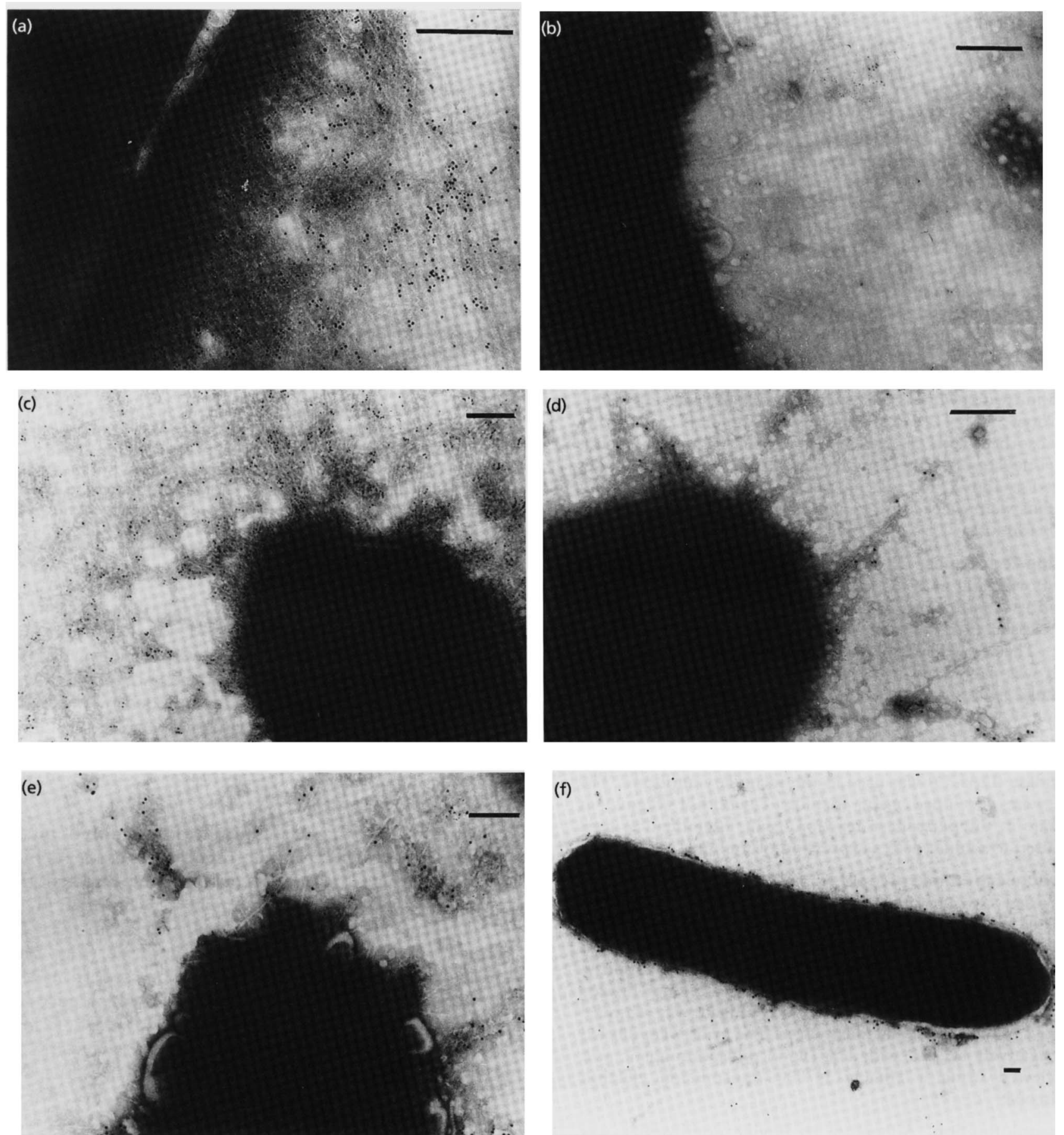

Fig. 5. Immuno-electron microscopy (a-e) of E. coli XL1-Blue containing the plasmids (a) pMM104, (b) pMM1041, (c) pMM1041 and pMM102, (d) pMM1041 and pMM301, and (e-f) E. coli XL1-Blue(pSS2192) containing the plasmids (e) pMM7013 and pMM8301, (f) pMM7013 and pMM8102. Recombinant strains were incubated in either anti-CS1 antibodies $(a-c$ and $f$ ) or anti-CFAll antibodies ( $d$ and e) followed by probing with Protein A-gold conjugates (10 nm). Bars, $200 \mathrm{~nm}$.

protein of CFA/I fimbriae (pMM8301) could complement the $\operatorname{cso} A$ mutation (pMM103). Heat-released extracts from E. coli XL1-Blue harbouring pMM103 complemented in trans either with pMM8102 encoding the $\operatorname{cso} A$ gene or with pMM8301 encoding the $c f a B$ gene were analysed by immunoblotting using anti-CS1 antibodies (Fig. 6a) and
anti-CFA/I antibodies (Fig. 6b). The CFA/I subunit protein was expressed from the recombinant strain containing the cso $A$ deletion mutation (pMM103) and pMM8301 bearing the $c f a B$ gene in trans (Fig. 6b, lane 5), while the CS1 antigen was not detected from the same recombinant strain (Fig. 6a, lane 5). A weak reaction of 


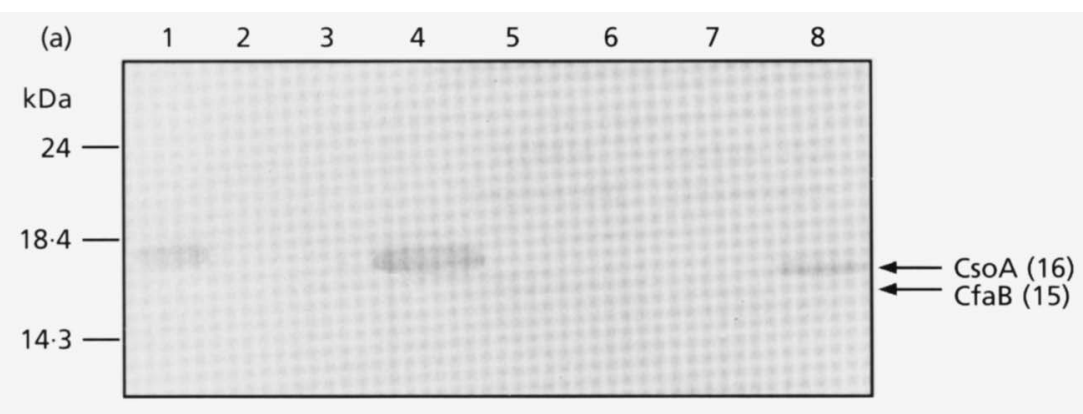

(b)

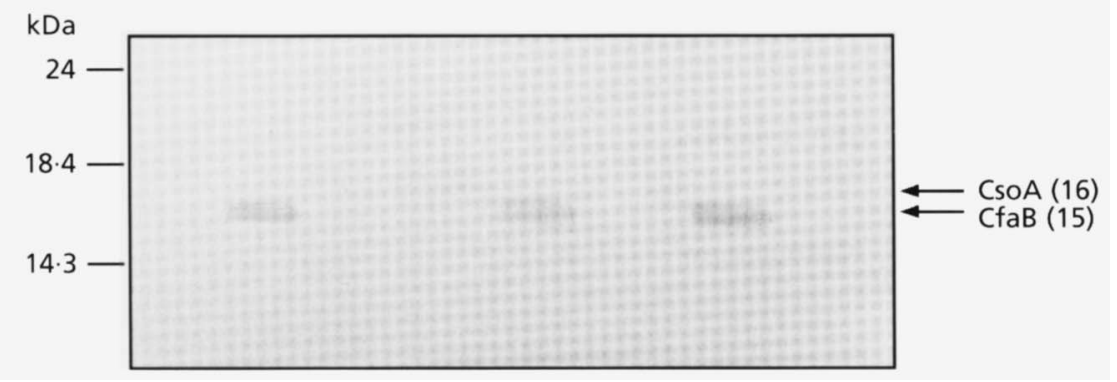

Fig. 6. Western blot analysis of expression of the CsoA antigen (a) and CfaB antigen (b) from recombinant plasmids expressing the heterologous antigen to the fimbrial genetic determinant. Heat-released extracts from wild-type ETEC and E. coli XL1-Blue harbouring recombinant plasmids with the DNA inserts described in Methods were probed with anti-CS1 antibodies (a) or anti-CFAl antibodies (b). Lanes: 1, strain E90a $\left(\mathrm{CS}^{+} 1^{+}\right) ; 2$, strain 54R118 $\left(\mathrm{CFA} / \mathrm{l}^{+}\right)$; 3, strain XL1-Blue(pMM103); 4, strain XL1Blue(pMM103 and pMM8102); 5, strain XL1Blue(pMM103 and pMM8301); 6, strain XL1Blue(pSS2192 and pMM7013); 7, strain XL1Blue(pSS2192, pMM7013 and pMM8301); 8, strain XL1-Blue(pSS2192, pMM7013 and pMM8102). The position of the CsoA or CfaB antigen is indicated on the right (size in $\mathrm{kDa}$ given in parentheses). Molecular mass standards are indicated on the left.
anti-CS1 antibodies with $\mathrm{CfaB}$ was observed (Fig. 6a, lane 5). Cross-reactivity between these subunits using polyclonal antibodies raised to either type of whole fimbriae was reported previously (McConnell et al., 1989). The CS1 subunit protein was detected in heat-released extracts from the $\operatorname{cso} A$ deletion mutant harbouring in trans pMM8102 encoding the cso $A$ gene (Fig. 6a, lane 4). The CFA/I subunit protein was not detected in heat-released extracts from this recombinant strain (Fig. 6b, lane 4). This confirmed the absence of cross-contaminating subunits in each complemented recombinant strain. Immunoelectron microscopy studies using anti-CFA/I antibodies revealed intact fimbriae labelled with Protein A-gold conjugates assembled on the surface of recombinant strains harbouring the plasmids pMM1041, encoding the deletion mutation in the cso operon, and pMM301, encoding the CFA/I subunit protein (Fig. 5d). This recombinant was also probed with anti-CS1 antibodies followed by incubation with Protein A-gold conjugates. The fimbriae observed were not labelled with gold conjugates (data not shown).

\section{The deletion mutation in the $c f a B$ gene is complemented when the $c f a B$ gene is provided in trans}

In contrast to the cloned genetic determinant for CS1 fimbriae, the $c f a$ genetic determinant possessed its own promoter region and, thus, the regulator $\mathrm{CfaD}$ or its homologue Rns, was required for expression. The homologue, Rns, encoded on pSS2192 was used in this study. A deletion was created in the $c f a B$ gene encoding the structural subunit protein of the CFA/I operon (pMM7013) (see Methods). The mutation created in the CFA/I operon was characterized using immuno-techniques in a similar manner to the characterization of the deletion mutation in the CS1 operon. Trans-complement- ation experiments were carried out with the CFA/I deletion mutant to assess the polarity of the mutation.

Immunoblot analysis showed that the $\mathrm{CfaB}$ antigen was not expressed from the recombinant strain XL1Blue(pSS2192) containing pMM7013, encoding the deletion in the $c f a B$ gene (Fig. $6 \mathrm{~b}$, lane 6 ). The $\mathrm{CfaB}$ antigen was detected when this mutation was complemented in trans with pMM8301, which encodes the $c f a B$ gene (Fig. $6 \mathrm{~b}$, lane 7 ; note also the weak cross-reaction with anti-CS1 antibodies Fig. 6a, lane 7). Agglutination of this recombinant strain by anti-CFA/I antibodies in the slide agglutination test indicated that this antigen was expressed on the cell surface of this strain. Furthermore, CFA/I fimbriae were detected by immuno-electron microscopy (Fig. 5e). These results indicated that this mutation was non-polar with respect to the genes downstream of $c f a B$ and that expression of only the structural subunit was abrogated.

\section{The CsoA antigen is surface expressed when the deletion mutation in the $c f a B$ gene is complemented by the cSOA gene expressed in trans}

The CsoA protein was expressed from the recombinant strain XL1-Blue(pSS2192) containing plasmids pMM7013 and pMM8102, encoding the $c f a B$ deletion mutation and the $\operatorname{cso} A$ gene, respectively, as shown by immunoblotting (Fig. 6a, lane 8). In addition, the CsoA antigen was expressed on the cell surface as detected by slide agglutination with anti-CS1 antibodies. Immunoelectron microscopy did not reveal this antigen as assembled fimbriae; instead Protein A-gold conjugates which bound to anti-CS1 antibodies interacting with the CsoA antigen appeared to be associated directly with the bacterial cell surface (Fig. 5f). The CFA/I subunit was not expressed from this recombinant strain (Fig. 6b, lane 8). 
Table 2. Summary of major antigens expressed from recombinant plasmids in transcomplementation experiments using immunotechniques and haemagglutination assays

\begin{tabular}{|c|c|c|c|c|}
\hline $\begin{array}{l}\text { Plasmid(s) in } \\
\text { E. coli XL-Blue }\end{array}$ & Genes present & $\begin{array}{c}\text { Major antigen } \\
\text { expressed* }\end{array}$ & $\begin{array}{l}\text { Cell surface } \\
\text { expressiont }\end{array}$ & $\begin{array}{c}\text { MRHA } \\
\text { phenotype } \neq\end{array}$ \\
\hline pMM102 & $\operatorname{cso} A$ & CsoA & - & - \\
\hline pMM104 & CS1 operon & CsoA & CS1 fimbriae & + \\
\hline pMM1041 & $\mathrm{CS} 1$ operon $\Delta c s 0 A$ & - & - & - \\
\hline $\begin{array}{l}\text { pMM1041 } \\
+ \text { pMM102 }\end{array}$ & $\begin{array}{l}\mathrm{CS} 1 \text { operon } \Delta c s o A \\
c s o A\end{array}$ & CsoA & CS1 fimbriae & + \\
\hline $\begin{array}{l}\text { pMM1041 } \\
+ \text { pMM301 }\end{array}$ & $\begin{array}{l}\operatorname{CS} 1 \text { operon } \Delta c s o A \\
c f a B\end{array}$ & $\mathrm{CfaB}$ & CFA/I fimbriae & + \\
\hline $\begin{array}{l}\text { pMM7013 } \\
+ \text { pSS2192 }\end{array}$ & $\begin{array}{l}\text { CFA/I operon } \Delta c f a B \\
r n s\end{array}$ & - & - & - \\
\hline $\begin{array}{l}\text { pMM7013 } \\
+ \text { pSS2192 } \\
+ \text { pMM8301 }\end{array}$ & $\begin{array}{l}\text { CFA/I operon } \Delta c f a B \\
r n s \\
c f a B\end{array}$ & $\mathrm{CfaB}$ & CFA/I fimbriae & + \\
\hline $\begin{array}{l}\text { pMM7013 } \\
+ \text { pSS2192 } \\
+ \text { pMM8102 }\end{array}$ & $\begin{array}{l}\text { CFA/I operon } \Delta c f a B \\
r n s \\
\operatorname{cso} A\end{array}$ & CsoA & CsoA antigen & + \\
\hline
\end{tabular}

* Detected by Western immunoblotting with anti-CS1 or anti-CFA/I antibodies.

† Detected by electron microscopy with anti-CS1 or anti-CFA/I antibodies.

$\ddagger$ MRHA, mannose-resistant haemagglutination.

The CS1 antigen was not detected in E. coli XL1Blue(pSS2192) containing plasmids pMM7013, encoding the deletion of the $c f a B$ gene in the CFA/I operon, and pMM8301, encoding the complementing $\mathrm{CFaB}$ antigen in trans (Fig. 6a, lane 7).

\section{Trans-complementation of the deletion mutations restores mannose-resistant haemagglutination}

Having characterized the deletion mutations in the subunit genes and determined that they were non-polar, we investigated the effect of each mutation on the adhesiveness of the respective fimbriae. The haemagglutination assay (the agglutination of bovine erythrocytes in a mannose-resistant manner) was used to assess the effect of the deletions of the structural subunit genes on fimbrial adhesiveness. Table 2 summarizes the results of the haemagglutination tests. The deletion in the $\operatorname{cso} A$ gene abolished the adhering ability of CS1 fimbriae, while complementation of this mutation with the $\operatorname{cso} A$ gene in trans restored adhesion. Similarly, deletion of the $c f a B$ gene abolished the adhering ability of CFA/I fimbriae, while complementation of this mutation with the $c f a B$ gene in trans restored adhesion. Thus, complementation of the deletion mutants with their respective structural subunit genes restored adhesion, demonstrating that these mutations do not have a polar effect on the functional expression of their respective fimbriae. Moreover, expression of the heterologous $\mathrm{CfaB}$ subunit protein in trans to the CS1 operon harbouring the deletion in the $\operatorname{cso} A$ gene, or expression of the heterologous CsoA subunit protein in trans to the CFA/I operon harbouring the deletion in the $c f a B$ gene, conferred the adhesion pheno- type on these recombinant strains. This demonstrated that CsoA, the structural subunit, played a role in the adherence of CS1 fimbriae.

\section{A minor subunit protein is not encoded in the DNA region downstream from the csoA gene}

Sequencing of the DNA region downstream from the cso $A$ gene, which was carried out independently in this study, was reported recently (Froehlich et al., 1994). Our sequence data in these coding regions (csoC and $c s o E$ ) are identical to those deposited by Froehlich et al. (1994) under accession number X76908 and accordingly are not repeated herein. The salient features of the sequence analysis were highlighted by Froehlich et al. (1994). In keeping with the $c 00$ nomenclature of the CS1 operon, Froehlich et al. (1994) have named the open reading frames $\operatorname{coo} C$ and $c o o D$, which correspond to $c s o C$ and $c s o E$, respectively.

Seven differences however, exist between the sequence data published in Fig.1 of Froehlich et al. (1994) and that deposited under accession number X76908. Translation of codons from nucleotides 3791-3805 should read 'Ser Phe Glu Ser Ser' and from nucleotides 3809-3014 should read 'Asn and Glu'. The codon GTG is omitted at nucleotide positions 4042-4044 and an extra codon, AGT, is inserted at position 4051-4053, resulting in the incorrect translation of this region of the published sequence. One hundred and twenty nucleotides have also been omitted from the published sequence at nucleotide positions 4363 through 4482. Finally, two codons, ATC and AAT, were inserted at positions 4843-4848 and the same two codons were omitted at positions 4903-4908. This resulted in the 
incorrect translation of this region of the published sequence.

In addition, sequencing of approximately $800 \mathrm{bp}$ of one strand of the DNA region downstream from the csoE gene (Fig. 3, the region between EcoRI and HindIII) revealed that approximately $200 \mathrm{bp}$ downstream from the $3^{\prime}$ end of csoE, insertion sequences are found. These sequences, similar to IS629 and IS2, are detailed by Froehlich et al. (1994), who sequenced both strands in this region. CsoC and $\mathrm{CsoE}$ do not share similarity with the structural subunit protein, CsoA, a property associated with minor subunit proteins of other fimbrial systems. Thus, this DNA region does not contain an open reading frame encoding a minor subunit protein which could act as an adhesin.

\section{DISCUSSION}

The interchangeability of genes of the CS1 and CFA/I fimbrial systems in mediating surface expression of their heterologous structural subunits in this study suggests a relatedness between these two fimbrial systems and certainly that similar modes of fimbrial biogenesis may exist. Three putative accessory proteins in each fimbrial system, $\mathrm{CsoB} / \mathrm{CsoC} / \mathrm{CsoE}$ and $\mathrm{CfaA} / \mathrm{CfaC} / \mathrm{CfaE}$, respectively, have been identified to be involved in assembly of fimbrial subunits. Of these, CsoE shows the lowest degree of amino acid sequence identity and similarity with its homologue protein, $\mathrm{CfaE}$ (see below). The putative accessory proteins of the CS1 fimbrial system could interact productively with the $\mathrm{CfaB}$ protein and direct its assembly into functional CFA/I fimbriae. In contrast, the surface expression, but not assembly, of the CsoA protein mediated by the accessory proteins of the CFA/I fimbrial system implies some functional deficiency which may relate to the interchangeability of the $E$ proteins. Alternatively, this result may reflect a property of the deletion mutation created in the CFA/I operon. A recent study examining the interchangeability of the type 1 and F1C fimbrial export proteins demonstrated that while replacement of the type 1 biogenesis apparatus with that of F1C fimbriae was successful in restoring the wild-type phenotype, the reverse was not as successful (Klemm et al., 1995).

The observation of heterologous assembly of fimbrial subunits was utilized to investigate if there was a similarity in structural organization between CS1 and CFA/I fimbriae. It was previously demonstrated, through biochemical studies, that the structural subunit protein, $\mathrm{CfaB}$, is the adhesin of the CFA/I fimbria (Bühler et al., 1991). Therefore, no adhesin is expressed from the CFA/I fimbrial system when the structural subunit protein is deleted. The absence of a minor subunit protein acting as an adhesin in this system allowed the examination of the role of the CsoA antigen in adherence, when it is expressed in trans to the plasmid expressing only the accessory components required for the biogenesis of CFA/I fimbriae.

In our study, the adhering property of CS1 fimbriae was shown to be conferred by its structural subunit protein,
CsoA, as is the case with CFA/I fimbriae. Deletion of the gene encoding the structural subunit of CS1 fimbriae and subsequent trans-complementation with the $\operatorname{cso} A$ gene demonstrates that the structural CsoA subunit makes a contribution to the adhesive property of CS1 fimbriae. However, the surface expression of the CsoA protein in a functionally adhesive manner, mediated by a heterologous fimbrial system (CFA/I) lacking its own adhesin, confirms that the CsoA protein specifies adherence.

Sequencing of the entire CFA/I genetic determinant did not reveal any gene encoding a minor protein subunit which could represent a putative adhesin (Jordi et al., 1992), thus confirming the biochemical study of Bühler $e t$ al. (1991). By analogy, in this study, and independently in that of Froehlich et al. (1994), the downstream DNA region of the CS1 genetic determinant was sequenced and revealed two open reading frames and sequences similar to insertion sequences. The proteins encoded by these open reading frames do not resemble a putative subunit protein which could act as an adhesin. Instead, the translated product of the $c s o C$ gene shares $63 \%$ amino acid identity and $84 \%$ amino acid similarity with the $\mathrm{CfaC}$ protein of the CFA/I fimbrial system, while the translated product of the $c s 0 E$ gene shows $53 \%$ amino acid identity and $75 \%$ amino acid similarity with the $\mathrm{CfaE}$ protein of the CFA/I fimbrial system (this study and Froehlich $e$ t al., 1994). Together with the observation that the CsoB, CsoC and CsoE proteins of the cso operon have been shown to be able to substitute for their CFA/I homologues, this strongly suggests that these proteins represent the biogenesis system of these fimbriae. However, these proteins do not show any similarity with the components of known biogenesis systems (Hultgren et al., 1991), even though CsoC has a molecular mass in the range of identified molecular ushers, and properties consistent with it being an outer-membrane protein. Therefore, the ancillary proteins of these two fimbrial systems may represent prototypes of an as yet undocumented assembly apparatus.

Recent studies on the immunogenicity of CFAs expressed by human ETEC demonstrate the ability of monoclonal antibodies against CFA/I to cross-react with and inhibit the haemagglutination property of such heterologous CFAs as CS1 and CS4 (Rudin \& Svennerholm, 1994; Rudin et al., 1994). It was concluded that a vaccine composed of bacteria expressing selected CFAs could induce protection against ETEC expressing a broader range of CFAs. The ability of the ancillary proteins of one such fimbrial system to mediate the surface expression of a subunit of another CFA fimbrial system, demonstrated in this study, opens up the possibility of the creation of a recombinant vaccine strain which expresses a number of heterologous CFAs by utilizing just one biogenesis apparatus.

\section{ACKNOWLEDGEMENTS}

Plasmid pNTP513 was kindly provided by Dr H. R. Smith, Central Public Health Laboratory, Colindale, London, UK. Plasmids pSS4180 and pSS2192 were kindly provided by S. G. J. Smith, Department of Microbiology, Trinity College, Dublin. 
We acknowledge Jane Twohig for technical assistance. This work was supported by the Health Research Board of Ireland, from whom M. M. received a research studentship.

\section{REFERENCES}

Altschul, S. F., Gish, W., Miller, W., Myers, E. W. \& Lipman, D. J. (1990). Basic local alignment search tool. J Mol Biol 215, 403-410. Buhler, T., Hoschutzky, H. \& Jann, K. (1991). Analysis of colonization factor antigen $\mathrm{I}$, an adhesin of enterotoxigenic Escherichia coli O78: H11 : fimbrial morphology and location of the receptor-binding site. Infect Immun 59, 3876-3882.

Caron, J., Coffield, L. M. \& Scott, J. R. (1989). A plasmid-encoded regulatory gene, rns, required for expression of the CS1 and CS2 adhesins of enterotoxigenic Escherichia coli. Proc Natl Acad Sci US A 86, 963-967.

Chang, A. C. Y. \& Cohen, S. N. (1978). Construction and characterization of amplifiable multicopy DNA cloning vehicles derived from the P15A cryptic miniplasmid. J Bacteriol 134, 1141-1156.

Cravioto, A., Scotland, S. M. \& Rowe, B. (1982). Hemagglutination activity and colonization factor antigens $\mathrm{I}$ and II in enterotoxigenic and non-enterotoxigenic strains of Escherichia coli isolated from humans. Infect Immun 36, 189-197.

Evans, D. G. \& Evans, D. J., Jr (1978). New surface-associated heatlabile colonization factor antigen (CFA/II) produced by enterotoxigenic Escherichia coli of serogroups $\mathrm{O} 6$ and O8. Infect Immun 21, 638-647.

Evans, D. G., Silver, R. P., Evans, D. J., Jr, Chase, D. G. \& Gorbach, S. L. (1975). Plasmid-controlled colonization factor associated with virulence in Escherichia coli enterotoxigenic for humans. Infect Immun 12, 656-667.

Froehlich, B. J., Karakashian, A., Melsen, L. R., Wakefield, J. C. \& Scott, J. R. (1994). CooC and CooD are required for assembly of CS1 pili. Mol Microbiol 12, 387-401.

Gaastra, W., Jordi, B. J. A. M., Mul, E. M. A., Hamers, A. M., McConnell, M. M., Willshaw, G. A., Smith, H. \& van der Zeijst, B. A. M. (1990). A silent regulatory gene $c f a D^{\prime}$ on region 1 of the CFA/I plasmid NTP 113 of enterotoxigenic Eschericbia coli. Microb Pathog 9, 285-291.

de Graaf, F. K. \& Gaastra, W. (1994). Fimbriae of enterotoxigenic Escherichia coli. In Fimbriae: Adbesion, Genetics, Biogenesis and Vaccines, pp. 57-88. Edited by P. Klemm. Boca Raton: CRC Press.

Harboe, N. \& Ingild, A. (1973). Immunization, isolation of immunoglobulins, estimation of antibody titre. In $A$ Manual of Quantitative Immunoelectrophoresis: Methods and Applications, pp. 161-169. Edited by N. H. Axelsen, J. Krøll \& B. Weeke. Oslo: Universitetsforlaget.

Higgins, D. G. \& Sharp, P. M. (1989). Fast and sensitive multiple sequence alignments on a microcomputer. Comput Appl Biosci 5, 151-153.

Hultgren, S. J., Normark, S. \& Abraham, S. N. (1991). Chaperoneassisted assembly and molecular architecture of adhesive pili. Annu Rev Microbiol 45, 383-425.

Jordi, B. J. A. M., van Vliet, A. H. M., Willshaw, G. A., van der Zeijst, B. A. M. \& Gaastra, W. (1991). Analysis of the first two genes of the CS1 fimbrial operon in human enterotoxigenic Eschericbia coli of serotype O139:H28. FEMS Microbiol Lett 80, 265-270.

Jordi, B. J. A. M., Willshaw, G. A., van der Zeijst, B. A. M. \& Gaastra, W. (1992). The complete nucleotide sequence of region 1 of the CFA/I fimbrial operon of human enterotoxigenic Escherichia coli. DN A Sequence 2, 257-263.

Klemm, P., Jørgensen, B. J., Kreft, B. \& Christiansen, G. (1995).
The export systems of type1 and F1C fimbriae are interchangeable but work in parental pairs. $J$ Bacteriol 177, 621-627.

Kusters, J. G. \& Gaastra, W. (1994). Fimbrial operons and evolution. In Fimbriae: Adbesion, Genetics, Biogenesis and Vaccines, pp. 189-207. Edited by P. Klemm. Boca Raton: CRC Press.

Laemmli, U. K. (1970). Cleavage of structural proteins during the assembly of the head of bacteriophage T4. Nature 227, 680-685.

Lerner, C. G. \& Inouye, M. (1990). Low copy number plasmids for regulated low-level expression of cloned genes in Eschericbia coli with blue/white insert screening capability. Nucleic Acids Res 18, 4631.

McConnell, M. M., Smith, H. R., Willshaw, G. A., Field, A. M. \& Rowe, B. (1981). Plasmids coding for colonization factor antigen I and heat-stable enterotoxin production isolated from enterotoxigenic Escherichia coli: comparison of their properties. Infect Immun 32, 927-936.

McConnell, M. M., Chart, H. \& Rowe, B. (1989). Antigenic homology within human enterotoxigenic Escherichia coli fimbrial colonization factor antigens: CFA/I, coli-surface-associated antigens (CS)1, CS2, CS4 and CS17. FEMS Microbiol Lett 61, 105-108.

Perez-Casal, J., Swartley, J. S. \& Scott, J. R. (1990). Gene encoding the major subunit of CS1 pili of human enterotoxigenic Escherichia coli. Infect Immun 58, 3594-3600.

Rudin, A. \& Svennerholm, A.-M. (1994). Colonization factor antigens (CFAs) of enterotoxigenic Escherichia coli can prime and boost immune responses against heterologous CFAs. Microb Pathog 16, 131-139.

Rudin, A., McConnell, M. M. \& Svennerholm, A.-M. (1994). Monoclonal antibodies against enterotoxigenic Escherichia coli colonization factor antigen I (CFA/I) that cross-react immunologically with heterologous CFAs. Infect Immun 62, 4339-4346.

Sambrook, J., Fritsch, E. F. \& Maniatis, T. (1989). Molecular Cloning: a Laboratory Manual, 2nd edn. Cold Spring Harbor, NY: Cold Spring Harbor Laboratory.

Savelkoul, P. H. M., Willshaw, G. A., McConnell, M. M., Smith, H. R., Hamers, A. M., van der Zeijst, B. A. M. \& Gaastra, W. (1990). Expression of CFA/I fimbriae is positively regulated. Microb Pathog 8, 91-99.

Scott, J. R., Wakefield, J. C., Russell, P. W., Orndorff, P. E. \& Froehlich, B. J. (1992). CooB is required for assembly but not transport of CS1 pilin. Mol Microbiol 6, 293-300.

Smith, H. R., Willshaw, G. A. \& Rowe, B. (1982). Mapping of a plasmid, coding for colonization factor antigen $I$ and heat-stable enterotoxin production, isolated from an enterotoxigenic strain of Escherichia coli. J Bacteriol 149, 264-275.

Smyth, C. J. (1982). Two mannose-resistant haemagglutinins on enterotoxigenic Escherichia coli of serotype O6:K15:H16 or Hisolated from travellers' and infantile diarrhoea. J Gen Microbiol 128, 2081-2096.

Smyth, C. J. (1986). Fimbrial variation in Eschericbia coli. In Antigenic Variation in Infectious Diseases, pp. 95-125. Edited by T. H. Birkbeck \& C. W. Penn. Oxford: IRL Press.

Smyth, C. J., Kaijser, B., Bäck, E., Faris, A., Mollby, R., Soderlind, O., Stintzing, G., Wadstróm, T. \& Habte, D. (1979). Occurrence of adhesins causing mannose-resistant haemagglutination of bovine erythrocytes in enterotoxigenic Escherichia coli. FEMS Microbiol Lett 5, 85-90.

Smyth, C. J., Marron, M. \& Smith, S. G. J. (1994). Fimbriae of Escherichia coli. In Escherichia coli in Domestic Animals and Humans, pp. 399-435. Edited by C. L. Gyles. Wallingford, UK: CAB International.

Stoker, N. G., Fairweather, N. F. \& Spratt, B. G. (1982). Versatile 
low-copy-number plasmid vectors for cloning in Escherichia coli. Gene 18, 335-341.

Towbin, H., Staehelin, T. \& Gordon, J. (1979). Electrophoretic transfer of proteins from polyacrylamide gels to nitrocellulose sheets: procedure and some applications. Proc Natl Acad Sci USA 76, $4350-4354$.
Willshaw, G. A., Smith, H. R. \& Rowe, B. (1983). Cloning of regions encoding colonisation factor antigen 1 and heat-stable enterotoxin in Escherichia coli. FEMS Microbiol Lett 16, 101-106.

Received 19 April 1995; revised 5 July 1995; accepted 12 July 1995. 